\section{LAS DETERMINACIONES GENÉRICAS EN LOS PROCESOS ADAPTATIVOS*}

\author{
José Antonio Pérez Bowie \\ Universidad de Salamanca \\ bowie@usal.es
}

\begin{abstract}
The translation of a literary text to the screen is usually conditioned by many factors derivated from the new context in which the adapted title must work. Among these we can count the conditions imposed on the original text by the cinematographic genre serving as a model in the translation process. This paper examines the problem and analizes three spanish films of the postwar period in which the literary work experiments an important transformation to adapted to exigences of cinematographic model.
\end{abstract}

KEY WORDS: Adaptation; film; literature; genres.

Los estudios contemporáneos sobre el fenómeno de la adaptación de textos literarios a la pantalla ponen de relieve el elevado número de factores implicados en tales operaciones. Se tiende, por ello, a abordarlas desde una perspectiva globalizadora, apoyándose en la teoría literaria reciente y superando las limitaciones de otros estudios anteriores basados en enfoques exclusivamente intra o intertextuales y que desatendian, por tanto, la ineludible consideración pragmática que este tipo de prácticas exige.

Se insiste, por una parte, en considerar la práctica adaptativa como la intervención sobre un texto ajeno en el que el autor vierte su propio universo a través de una escritura personal; ello ha llevado a concebir la adaptación en términos de reescritura (Ropars, 1975, 1981 y 1990), de apropiación (Vanoye, 1989 y 1996) o de transformación (Coremans, 1990). Esta última autora señala la imposibilidad de que existan estructuras narrativas autónomas, independientes de su realidad semiótica y niega la existencia de un único sentido transparente correspondiente a la intención del sujeto enunciador, dado que la coherencia de la adaptación es el resultado de un ajuste permanente entre un locutor y un auditorio a través de una cultura variable; ello le lleva a defender el carácter abierto del

\section{GENRE DETERMINATIONS IN THE ADAPTATIVE PROCESSES}

RESUMEN: El traslado de un texto literario a la pantalla suele estar condicionado por diversos factores derivados del nuevo contexto en el que el título adaptado debe funcionar. Entre ellos están los condicionamientos que ejerce sobre la obra originaria el género cinematográfico que sirve de modelo para el proceso adaptador. En el presente trabajo se reflexiona sobre esas determinaciones y se analizan tres ejemplos del cine español de postguerra en los cuales la obra literaria sufre una transformación considerable para adecuarse a las exigencias del modelo cinematográfico elegido.

PALABRAS CLAVE: Adaptación; cine; literatura; géneros.

texto como lugar de múltiples interpretaciones cada una de las cuales es una aproximación a la estructura subyacente o a la regla sistemática creada por el juego de las relaciones textuales. Por eso, en vez de adaptación prefiere hablar de transformación fílmica de un texto literario y la define como "el resultado de un acto interpretativo que actualiza las estructuras del texto literario situado en unas nuevas condiciones pragmáticas y poniendo en relación al sujeto enunciador, al destinatario y al intertexto (Coremans, 1990, 34). Otros autores introducen la noción de espectador implícito definido como el resultado "de la suma de elementos formales y diegéticos del propio discurso que, desde él, prefigura el modo en que debe ser recibido cooperativamente por sus destinatarios reales" (Villanueva, 1999, 207-208).

Este giro decididamente pragmático de los estudios sobre la adaptación es compartido por la mayoría de los autores que se ocupan de ella, como Catrysse (1992), Serceau (1999) o Stam (2000 y 2005). Todos ellos dedican una especial atención al denominado (en expresión de Catrysse) contexto de llegada, cuyas diferencias con respecto al contexto de partida resulta imprescindible tener en cuenta para comprender la serie de transformaciones experimentadas por el texto literario al convertirse en filme. Catrysse 
ha analizado con minuciosidad ese proceso de transformación apoyándose en la Teoría de los Polisistemas de Even Zohar, y se preocupa de examinar no sólo cómo el Texto2 ha adaptado el Texto1 sino también en qué medida la política de selección de los elementos primeros y el proceso de transferencia se han producido en función del papel que el nuevo texto desempeñará al ubicarse en un polisistema distinto. El funcionamiento de aquél en el polisistema de llegada obliga a abordar la adaptación no en función de relaciones predefinidas de fidelidad 0 adecuación al texto de partida sino de la medida en que es percibida y evaluada por el público y la crítica como adaptación. Por otra parte, Catrysse se interroga sobre la posición -central o periférica- que la adaptación fílmica ocupará en el nuevo polisistema y sobre los mecanismos sistémicos que han determinado la selección del texto objeto de la adaptación, mecanismos que constituyen un conjunto complejo y evolutivo de factores de diversa índole: histórica, política, estética, cultural, etc.). Catrysse señala que no ha de excluirse tampoco la interferencia de factores provenientes de los que denomina "sistemas intermediarios", lo que le conduce a interrogarse sobre el carácter mediato o inmediato del proceso de adaptación, y a preguntarse si los productores del film se han basado en el texto original o han recurrido a textos intermedios (Catrysse, 1995, 34-39).

La riqueza teórica que encierran estos trabajos nos proporciona un considerable arsenal de recursos para abordar el fenómeno de la adaptación desde el enfoque omnicomprensivo que exige su consideración pragmática. En las páginas que siguen voy a centrarme en una cuestión concreta que servirá para ejemplificar las determinaciones que el contexto de llegada ejerce sobre el texto de partida y poner con ello de manifiesto la complejidad inherente a toda operación de trasvase de una obra literaria a la pantalla; ese caso concreto será el de las mutaciones a que el texto de partida puede verse sometido para adecuarse al esquema genérico fílmico desde el que se plantea la adaptación.

Ello nos obliga a enfrentarnos con la polémica categoría de género y con las radicales diferencias que dicha categoría presenta en el ámbito literario y en el cinematográfico. En el campo de la literatura, tras siglos de tradición normativista, la teoría moderna se ha caracterizado por limitarse a subrayar su función descriptiva, apelando a la idea del relativismo y mutabilidad de la forma, según las épocas históricas y las culturas; no ha interesado tanto construir un sistema cerrado y jerárquico como hallar los aspectos comunes de los géneros, las condiciones que convergen para explicar cómo en un momento histórico dado el género articula la relación de la literatura con la tradición que lo produce. Las posiciones recientes van, sin embargo, más lejos y tienden a afrontar el género como un elemento "modificador" y no ya "modelizador"; al ser concebido como campo de modificación, se destaca la función transformativa, por la cual lo que se valora es su inestabilidad, la desviación, su capacidad dialéctica entre la conservación y la innovación. Schaeffer, el teórico principal de este nuevo enfoque, prefiere hablar más que de género de genericidad hipertextual poniendo el acento no en el estudio de las convenciones sino en el de las transformaciones (todo texto es un hipertexto que deriva de textos precedentes [hipotextos] a través de operaciones de transformación o imitación), es decir, en el estudio de "las modalidades de la creatividad literaria" (Schaeffer, 1989, 159-165).

En el ámbito cinematográfico, por el contrario, la categoría de género posee unas características distintas por ser fruto no de una tradición académica y normativista sino de la interrelación entre los intereses económicos de las productoras, la reflexión de la crítica y las exigencias de los públicos espectadores ${ }^{1}$. Para Rick Altman, uno de los principales teóricos de la cuestión, no existe posibilidad de dar una definición típicamente aristotélica y rigurosamente temporal del género cinematográfico y tampoco considera que se pueda hablar del mismo como de un sistema cerrado que se alimente de sus propias variantes ni de que puedan interpretarse las construcciones genéricas como un reflejo de la realidad socioeconómica. El género supone ante todo, para Altman, la existencia de convenciones aceptadas como tales por el espectador, ya que el público participa en la producción del género en tanto éste "da forma a su público, suscita en él expectativas y lo somete a las actitudes que imponen diferencia y repetición". Para que un género exista hace falta, pues, que pueda ser reconocido como tal: el espectador espera algo que se le ha prometido, pero, a la vez, espera algo nuevo. La repetición (el estereotipo, el tópico) está, pues, sometida a variaciones, las cuales constituyen el pequeño rasgo diferencial que permite al aficionado, debido a su saber, observar la desviación y gozar con ello (Altman, 2000, 106-107). Altman retoma la afirmación de Alain Masson, de que los reajustes 
acaban en general en un enriquecimiento y la memoria del género termina por dibujarse como un registro de variaciones más que como una homogeneidad; y sostiene que en el cine no hay una tradición homogénea, una iconografía fija o una forma regular sino que por todas partes existe previsión, es decir "error, reajustes, modulaciones..." por lo que la historia de los géneros cinematográficos es "la de las continuas variaciones a velocidades variables, con encuentros, choques de frente, desapariciones, metamorfosis..." (Altman, 2000, 107-108).

Pero el necesario reconocimiento del género por parte del espectador exige admitir la existencia de unos imprescindibles esquemas genéricos, que son los que nos permiten, en definitiva, seguir utilizando la mencionada categoría. Michel Serceau destaca el papel que tales esquemas desempeñan en los procesos adaptativos $y$, de acuerdo con la tesis central que preside su trabajo (el análisis de la adaptación no consiste sólo en medir las convergencias y/o los desvíos de la práctica del cine y de la concepción del lenguaje cinematográfico de la que ella emana con la evolución de la literatura entendida a la vez como lengua y como escritura), afirma que la adaptación ha de ser abordada también "como manifestación(es) genérica(s) y pragmática(s) en las que es necesario examinar cómo y en qué medida prorrogan esos aspectos del género novelesco y literario negados, trascendidos o disueltos por la evolución de la novela o de la literatura; en qué medida contribuyen a conferirles un carácter secundario o en elevarlos de nuevo a la condición de primarios" (Serceau, 1999, 112). Se apoya en la recomendación de Etienne Fuzellier ${ }^{2}$ de considerar la literatura no como un repertorio de obras para transponer, sino como una herencia de temas y métodos y de abordar los hechos literarios a un nivel más profundo y más amplio: el de los temas, el de los géneros, el de los estilos, el de las elecciones estéticas. Esos testimonios de filiación con los géneros y los estilos literarios, afirma citando a Fuzellier, no han de buscarse tanto en las adaptaciones en sí mismas como en "los tipos de organización del film".

Serceau recurre también a Jean-Marie Schaeffer y apoya su idea de sustituir la etiqueta genérica por la noción de genericidad textual, ya que el género ha de ser entendido como una categoría dinámica, como proceso de generación y de perpetuas mutaciones en el cual concurre a la vez la actividad del emisor y del receptor. Por ello, una etiqueta de género no basta, por tanto, para identificar el texto de modo global, ya que los términos que designan los géneros raramente se refieren a un conjunto de características o de propiedades textuales recurrentes. Esta afirmación es aún más cierta -afirma- cuando se habla de cine, pues el género cinematográfico se refiere a un estado histórico de esos géneros literarios que debe ser precisado; aparte de que la referencia a un género literario no basta para definir a un género cinematográfico, pues éste implica otras filiaciones y dependencias (Serceau, 1999, 112-114).

La adaptación de textos literarios a la pantalla se encuentra, pues, vinculada de manera muy estrecha a la problemática de los géneros cinematográficos; bien sea porque, en la mayoría de los casos, el texto elegido para su traslado a la pantalla ha de adecuarse a las exigencias del molde genérico por el que haya optado el realizador, o bien porque éste decide transgredir el molde esperable por considerarlo exponente de una estética periclitada o expresión de una ideología que no comparte. En el primer caso nos hallamos ante realizaciones rutinarias que suelen implicar una devaluación o simplificación de la profundidad del texto literario, cuando no una manipulación si el género de aquél no encuentra adecuación en ninguno de los modelos cinematográficos vigentes; el segundo caso, por el contrario, suele ser el de los realizadores que asumen el riesgo de plantear problemas inéditos e intentar su solución, sea o no satisfactoria, conscientes de que la auténtica creación consiste en salirse de las propuestas estereotipadas y evitar la repetición de las fórmulas consagradas por el uso. Cabe también la posibilidad de que la opción por un molde genérico distinto del esperable no responda a ningún propósito transgresor sino que esté dictada por imperativos estrictamente comerciales. En todo caso, las determinaciones del molde genérico elegido para llevar a cabo el trasvase a la pantalla del texto literario resultan decisivas para juzgar el resultado de la operación. Vamos a comprobarlo en las páginas que siguen tomando como ejemplo algunos títulos de la producción cinematográfica española de los años 40 y 50.

\section{Huella de luz (Rafael Gil, 1942)}

Huella de luz es la adaptación de un relato homónimo de Wenceslao Fernández Flórez caracterizado, como la mayoría de los que escribió el autor durante la etapa 
de preguerra, por un pesimismo nihilista y una profunda misantropía. Se narra la historia de un oficinista, Federico Saldaña quien, desahuciado por los médicos a causa de una enfermedad incurable, es obsequiado por su jefe con una estancia en un lujoso balneario. Alli, disfrutando del dinero y de los trajes que le ha cedido su benefactor, lleva una vida de millonario y vive un romance con Lelly, una rica heredera alojada en el mismo establecimiento. La superchería se descubre cuando la madre de Federico acude a visitarlo; él huye sin enfrentarse con Lelly y la escena final nos lo presenta en su humilde habitación escribiendo retrospectivamente el relato de su aventura mientras espera la muerte y tras haber roto, sin abrirla, una carta de su amada.

El tono pesimista y el nihilismo del relato de Fernández Flórez no resultaban demasiado compatibles con las historias evasivas, acriticas y frecuentemente aleccionadoras que presentaba el cine español de la inmediata posguerra cuando se acercaba a la realidad presente. De ahí que Rafael Gil sometiese el texto, en colaboración con el propio autor, a una reelaboración profunda para adecuarlo a un modelo fílmico prestigiado y en plena sintonía con los intereses de nuestra industria cinematográfica y de sus mentores ideológicos: el de la comedia norteamericana cultivado por directores como Frank Capra, Ernst Lubitsch o Howard Hawks y caracterizado por su celebración de lo cotidiano y su visión optimista de la existencia, que exigian inevitablemente el happy end ${ }^{4}$.

El texto originario sufre, así, una serie de modificaciones que lo hacen prácticamente irreconocible: La enfermedad terminal del personaje, que pasa a llamarse Octavio, es sustituida por una debilidad pasajera motivada por el cansancio con lo que se suprime la visión privilegiada que proporcionaba al personaje la cercanía de la muerte con su consiguiente carga de neurastenia y sentimiento de vacío. La apatía y soledad del protagonista es transferida, en cambio, a un personaje de escaso relieve en el relato de Fernández Flórez: el jefe de Octavio, el empresario Sánchez Bey, a quien se nos presenta como un hombre triste a pesar de su fortuna como consecuencia de no haberse podido casar con la mujer de sus sueños, cuya fotografía sigue guardando en un cajón de su escritorio. El romance entre Saldaña y Lelly se completa, así, con una segunda línea argumental, pues aquella mujer resulta ser la madre de Lelly y Sánchez Bey va a proyectar la realización de su sueño en su empleado facilitando la boda de éste con la chica.

Se añade, por otra parte, un incidente al argumento que sirve para que Saldaña se gane la confianza y el aprecio de su jefe: Dos agentes negociadores de la imaginaria república de Turolandia llegan al hotel en busca de un fructífero contrato para su pais (resultan evidentes los ecos de Ninotchka, de Lubitch); el apoderado de Bey intenta traicionar a su jefe pactando con Andrés Medina (padre de Lelly y antiguo competidor de Bey) para hacerse ambos con dicho contrato a espaldas de aquél. Saldaña descubre la maniobra y pone al corriente a Bey. Éste se persona en el hotel y consigue el contrato frustrando las expectativas de su competidor. Cuando Lelly descubre la mentira ideada por Saldaña durante una visita de la madre de éste al balneario, el joven abatido regresa con su madre sin despedirse de ella. Sánchez Bey interviene para lograr la reconciliación, firma un pacto amistoso con Medina y nombra a Saldaña su apoderado.

En lo que se refiere al tratamiento formal, la película elimina la narración retrospectiva de la novela, que comenzaba con Federico, ya de vuelta a su humilde casa, escribiendo el relato de su aventura y de los días de ilusión vividos, antes de morir); dicha analepsis resultaba incompatible con el tratamiento optimista que se da a la historia, ya que inducía a una lectura pesimista al estar la amenaza de la muerte presente desde el principio. A ese pesimismo contribuía también la narración autobiográfica del relato literario, con las desencantadas reflexiones del protagonista, de las que se prescinde en la versión cinematográfica. La introducción de una historia paralela -la de los amores frustrados entre Sánchez Bey y la madre de Lelly- contribuye a potenciar la dimensión optimista de la historia de Octavio, que funciona como elemento compensador que permite al empresario, proyectándose en su joven empleado, la realización sus sueños. Por último, una tercera trama, la del sustancioso contrato con la república de Turolandia, aparte de añadir una nueva dosis de complejidad argumental y proporcionar un toque cosmopolita (dos caracteristicas del género), funciona como el factor desencadenante del ascenso social del protagonista, quien podrá aspirar a una boda de igual a igual con su amada ${ }^{5}$.

El resultado de la operación adaptadora es, pues, una transformación radical de los contenidos y la intenciona- 
lidad del texto originario, el cual se convierte en pretexto para la elaboración de un producto adscribible a un esquema genérico de gran éxito popular y rentable tanto desde una perspectiva económica como ideológica. El responsable de dicha operación, Rafael Gil (que contó -no hay que olvidarlo- con la colaboración del propio autor), logra un filme bastante asimilable a los presupuestos del molde elegido, sin recurrir, como sucede en otras películas del momento, a la conjugación del patrón dominante de la comedia hollywoodiense con las formas culturales enraizadas en la tradición nacional y dotadas de gran raigambre popular 6 .

\section{Las inguietudes de Shanti Andía (Arturo Ruiz Castillo, 1946)}

Frente al relativo éxito en la adecuación de un texto literario a un modelo cinematográfico foráneo (con la consiguiente tergiversación del sentido originario) que supuso Huella de luz, el ejemplo que a continuación comento ha de ser considerado como un fracaso por la precariedad con la que se aborda un género cinematográfico, la película de aventuras marítimas, que exigía un considerable despliegue de medios técnicos. La elección de una novela de Pío Baroja puede resultar sorprendente en el contexto de la inmediata posguerra, pero se trataba de un texto ideológicamente aséptico y por ello tolerable para la ortodoxia dominante.

La razón principal de su trasvase a la pantalla fue sin duda la idoneidad que presentaba para el intento de ampliar los estrechos márgenes genéricos en los que se movía la producción española en aquellos momentos, limitada casi exclusivamente a los subproductos folklóricos, al filme histórico de exaltación de las gestas del pasado, al melodrama de ambientación decimonónica o a la reproducción de moldes de probado éxito en los escenarios como la comedia burguesa o el sainete. La propuesta de Ruiz Castillo apuntaba hacia un género inédito en la filmografía española, la película de aventuras que llevase a la pantalla la tensión y el dinamismo del romance novelesco del cual Baroja fue uno de los escasos cultivadores en nuestra literatura. Los numerosos paratextos que acompañaron al estreno del filme (declaraciones de sus responsables, gacetillas publicitarias, críticas, etc.) así lo confirman.
El molde genérico del que partió el trabajo de Ruiz Castillo era, obviamente, el filme de piratas y aventuras marinas, con unos códigos rigurosamente establecidos y de fuerte implantación en la producción hollywoodiense desde hacía más de una década; recuérdense los títulos inaugurales de La isla del tesoro (Víctor Fleming, 1934) o El capitán Blood (Michael Curtiz, 1935), origen de una larga secuela de filmes entre los cabe citar Piratas del mar Caribe (Cecil B. DeMille, 1942), El pirata y la dama (Mitchell Leisen, 1944) o El capitán Kidd (Rowland W. Lee, 1945). El ritmo y la plasticidad inherentes a este tipo de narración cinematográfica exigían un despliegue de medios que no estaban al alcance de la rudimentaria y artesanal industria española del momento; por ello Las inquietudes de Shanti Andía abusó de la recreación en estudio de espacios exteriores, de la ubicación de la acción en espacios interiores o del oscurecimiento de la imagen en momentos cruciales ${ }^{7}$. Esa precariedad de medios provocó que la película de Ruiz Castillo se alejase de los estilemas del género en el que pretendía inscribirse para reiterar paradójicamente los de uno de aquellos otros géneros dominantes en la cinematografía española de la época frente a los que se proponía como intento de ruptura: el melodrama de ambientación decimonónica, calificado irónicamente como "cine de levita"; los decorados de cartón piedra, los interiores recargados y oscuros, el vestuario de guardarropía, la interpretación afectada y el engolamiento en la dicción de los actores, el abuso de los claroscuros y la teatralidad del diálogo son rasgos que Las inquietudes de Shanti Andía comparte con muchos de los filmes coetáneos; y no sólo los adscribibles al molde genérico señalado, sino a la mayoría de los filmes españoles de la época, por lo que hay que admitir la existencia de un look de producción que impregna de modo sistemático cuanto se rueda en nuestros estudios $y$, en el caso de la película que nos ocupa, terminó lastrando la apertura genérica que su director pretendía. Unas declaraciones del propio Ruiz Castillo previas al rodaje resultan muy significativas a este respecto: se refiere en ellas a que pretende hacer "una película española en la que aparecerá el Mar (sic) sin camouflage ni transparencias y cuya única subordinación a los modos y las modas de la producción nacional es la época: el Romanticismo" (Luces, 1945) sin ser consciente del lastre de artificiosidad que imponía a las producciones españolas esa fascinación por un romanticismo exclusivamente epidérmico y radicalmente incompatible con el "cine a cuerpo limpio" que, en esas mismas declaraciones, pretendía.

ARBOR Vol. 187748 marzo-abril [2011] 305-315 ISSN: 0210-1963

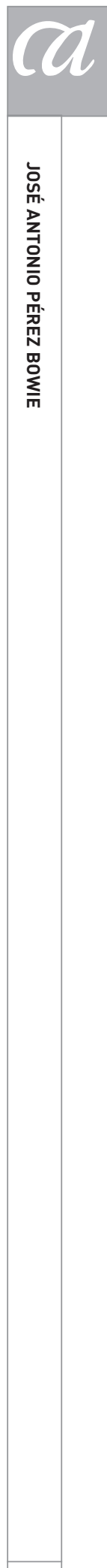

309 
La adecuación del texto barojiano al patrón cinematográfico elegido obligó, por otra parte, a someterlo a un conjunto de manipulaciones considerable. Las inquietudes de Shanti Andía es un relato de aventuras cuya instancia narradora es el personaje protagonista; pero las aventuras de éste ocupan un espacio casi irrelevante en el conjunto de la novela, que se centra más en el personaje del tío Juan de Aguirre y en la reconstrucción de su historia por Shanti a través de las informaciones que va recabando de diversos interlocutores. La narración se presenta, pues, en una estructura de considerable complejidad en la que el narrador autodiegético actúa como narratario y transcriptor de diversos relatos (orales y escritos) a partir de los cuales va reconstruyendo la historia de su misterioso tío; a ellos se suman, además, como suele ser habitual en las novelas barojianas, otros varios relatos que dan cuenta de historias colaterales. El autor articula todos esos materiales en un esquema cronológico de notable complejidad que le permite una hábil dosificación de las informaciones mediante la que atrapa desde el primer momento el interés del lector.

Al trasladar el texto barojiano a la pantalla, Ruiz Castillo, aparte de enfrentarse a la inevitable y comprensible selección de materiales, hubo de hacerlo simultáneamente a la simplificación del diseño compositivo; pero a pesar de ello la narración en segundo grado mediante la que se trasmiten en la novela muchos de los fragmentos de la historia sigue demasiado presente en el filme, por lo que éste se resiente de un exceso de discursividad. Por ejemplo, gran parte de la aventura de Juan de Aguirre a bordo de El Dragón no es visualizada sino narrada oralmente por Itchaso; de igual modo, la prisión de Aguirre en Inglaterra, su fuga, la boda con la escocesa y los flecos finales de la historia son narrados por Shanti al propio Baroja en la secuencia final. Incluso se llega a incluir informaciones en torno a personajes de la novela sobre los que el espectador no ha tenido ninguna información previa, como sucede en los comentarios que don Ciriaco hace a Shanti sobre la boda de Dolorcitas, la fuga de la madre con un amante y la muerte de don Matías.

La drástica selección de materiales y su reordenación, de acuerdo con una cronología más lineal, dan, sin embargo, como resultado, una historia coherente que puede ser seguida con facilidad por el espectador. La estructuración de la historia como un largo flash-back en el que Shanti maduro recuerda su vida y el guiño metaficcional de la última secuencia en la que el protagonista y su esposa narran su historia al propio Baroja, para que la utilice en una novela, son los únicos elementos que remiten a la complejidad del texto de partida.

Las inquietudes de Shanti Andía puede, pues, considerarse otro ejemplo ilustrativo de las determinaciones que condicionan cualquier práctica adaptativa. Aunque en este caso, como he señalado, el intento de ampliar los márgenes genéricos de la producción cinematográfica española hacia un modelo consolidado y cultivado con éxito en otros países fracasó por la precariedad de medios de nuestra industria, por la inercia de unos modelos de producción fuertemente implantados y por la complejidad narrativa del texto con relación al tipo de relato que el género pretendido demandaba ${ }^{8}$.

\section{A LAS CINCO DE LA TARDE (JuAn Antonio Bardem, 1960)}

Este filme de Bardem nos ofrece un nuevo e interesante ejemplo de las mutaciones que el patrón genérico al que se adecua la adaptación cinematográfica de un texto literario puede determinar en los contenidos y en la estructura de aquél. Aunque en este caso las mutaciones no afectaron sólo al texto de partida sino que el realizador transgredió sistemáticamente las reglas del (sub)género en que presumiblemente habia de inscribirse su trabajo -la película de toros- para optar por otro molde genérico que le permite llevar a cabo una crítica a fondo de aquel cine y del universo que presentaba.

En A las cinco de la tarde Bardem lleva a cabo una reelaboración a fondo del drama La cornada, de Alfonso Sastre, añadiéndole además elementos de un guión que el propio realizador tenía escrito sobre el mundo taurino titulado $L a$ fiera. El drama de Sastre abordaba desde una perspectiva crítica el universo de la fiesta nacional chocando de lleno con los enfoques puramente folcloristas y complacientes con que hasta entonces se la había tratado desde los escenarios (El niño de las monjas, de López Nuñez, o Currito de la Cruz, de Pérez Lugín, entre otros $)^{9}$; pero esa crítica a uno de los signos más celebrados de la españolidad no dejaba de ser un pretexto para adentrarse en otros niveles 
más profundos que abarcaban una dimensión social (la explotación del hombre por el hombre) e incluso metafísica (el mito de Saturno, devorador de sus propias criaturas). A su vez, en el plano formal, se produce una ruptura con las servidumbres de la puesta en escena naturalista mediante la que se subraya la condición abstracta del tema y se evita cualquier intento de identificación localista, especialmente mediante la insistencia en una gama cromática de grises y la incorporación de efectos sonoros y luminosos desrealizadores destinados a provocar la incomodidad y el distanciamiento del espectador y evitar los mecanismos de identificación emocionales. El propio Sastre, quien firmó el guión conjuntamente con Bardem, admitió de modo explícito que el proyecto no se trataba de un mero trasvase a la pantalla de su texto teatral y asumió que éste había servido de base a un ejercicio de "reescritura" que suponía una organización diferente de sus materiales

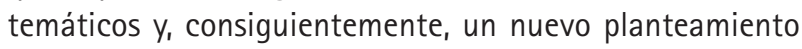
estructural ${ }^{10}$.

El drama de Alfonso Sastre suponía un buen punto de partida para el cine transgresor y de denuncia social en el que estaba embarcado Bardem. Sus afinidades ideológicas con el mensaje que proponía La cornada (la denuncia de la explotación del hombre por el hombre) y lo que ésta tenía de intención desmitificadora al desenmascarar el lado oscuro de la fiesta más representativa de la España folclórica, abordada hasta entonces por el cine desde una óptica exclusivamente idealizadora, fueron elementos que debieron de pesar en la decisión de Bardem de llevarla a la pantalla".

Para ello procede a una reescritura total del drama de Sastre, introduciendo una considerable cantidad de nuevos elementos. Esa reescritura es, por lo demás, una práctica habitual en las adaptaciones llevadas a cabo por el realizador, en unos casos con resultados más satisfactorios que en otros: basta para comprobarlo comparar Calle Mayor con Sonatas. Pero si en estos dos ejemplos, la reescritura de los textos respectivos de Arniches y de Valle-Inclán se explicaba por la tergiversación que Bardem propone de sus mensajes, no es el caso del drama de Sastre, con quien se encuentra en completa sintonía ideológica. Su labor de reescritura hay, pues, que entenderla como exigencia del marco genérico en el que Bardem quería situar su película $y$ al que en seguida me voy a referir; ese nuevo modelo le obligaba a una intensificación de los efectos dramáticos y a acentuar, a la vez, dentro del esquema simétrico en el que se insertan las figuras del drama, las diferencias entre sus roles respectivos.

En el caso de $A$ las cinco de la tarde cabe hablar, en primer lugar, de un modelo negativo, el género taurino, de larga trayectoria en el cine español. Al asumir Bardem la actitud crítica frente a la fiesta nacional que entrañaba el texto de Sastre y proponerse como objetivo, al igual que éste, mostrar los aspectos más sórdidos de la misma, se sitúa necesariamente frente a la visión idealizada y complaciente que caracterizaba a los filmes precedentes de tema taurino. Los numerosos títulos que integran el género insisten en la glorificación de la fiesta y los conflictos que proponen se centran habitualmente en una problemática individual (la rivalidad amorosa y/o profesional entre dos diestros, la trayectoria del héroe desde la miseria hasta el triunfo, la amistad traicionada, la oposición entre la novia fiel y casta y la mujer malvada que seduce al torero y lo obliga a exponerse en los ruedos, etc.) con una fuerte propensión al melodramatismo. Recuérdense títulos como El traje de luces (Edgar Neville, 1947), Currito de la Cruz (Luis Lucia, 1948), Tercio de quites (Gómez Muriel, 1951) y, ya en color, Tarde de toros (Ladislao Vajda, 1955), El niño de las monjas (Ignacio F. Iquino, 1959), Los clarines del miedo (Antonio Román, 1958), El Litri y su sombra (Rafael Gil, 1959) o El traje de oro (Julio Coll, 1959) por citar sólo algunos de los más cercanos al filme que nos ocupa. Éste utiliza como referente negativo todos esos títulos precedentes evitando no sólo cualquier mención complaciente de la fiesta sino de la corrida en sí misma que es el núcleo articulador de cualquier filme del género (la película finaliza en el momento en que comienza el paseillo); las escasas referencias taurinas que se insertan están, por su carga de connotaciones negativas, en las antípodas de las prodigadas por aquéllos: planos amenazantes de los toros enchiquerados, de la plaza vacía con los tendidos barridos por el viento, imágenes sangrientas del matadero que aparecen como la pesadilla del diestro, etc.

Junto a ese modelo frente al que el filme de Bardem reacciona transgrediéndolo, cabe hablar de un modelo positivo que pesó indudablemente en la opción del realizador: el género boxístico al que el cine hollywoodiense había recurrido con frecuencia durante los años 40 y 50 utilizando la figura del púgil manejado por un manager sin escrúpulos y preso en un mundo de corrupción como vehículo de sus 
mensajes críticos sobre la sociedad norteamericana. Entre la larga lista de títulos del género, que actuaron, trasponiendo la situación al universo taurino, como referentes de Bardem pueden citarse Kid Galahad (Michael Curtiz, 1937), Ciudad de conquista (Anatole Litvak, 1940), Cuerpo y alma (Robert Rossen, 1947), El ídolo de barro (Mark Robson, 1949), Noche en la ciudad (Jules Dassin, 1950), Tongo (Robert Wise, 1951) o Más dura será la caida (Mark Robson, 1956). De hecho, entre los planes de Bardem, tras finalizar Sonatas, estaba la realización de un filme sobre el mundo del boxeo y pensaba para ello en una adaptación de la novela de Ignacio Aldecoa Young Sánchez, pero el saber que Visconti se encontraba rodando un filme sobre el tema (Rocco y sus hermanos) lo disuadió de su propósito (Cerón Gómez, 1998, 172). En la obra de Sastre, que acababa de estrenarse, encontró un vehículo para desarrollar su mensaje de denuncia de las relaciones de explotación entre los seres humanos, convirtiendo al personaje del manager desalmado y manipulador en un empresario taurino lo que le permitía a la vez exhibir, como he señalado, la cara oculta de ese mundo sistemáticamente idealizado por los filmes españoles que lo abordaban. La transposición de los esquemas argumentales del género boxistico al taurino le lleva a incrementar de modo considerable la presencia de la figura del torero fracasado, que en el texto teatral de Sastre era irrelevante, confiriendo a la figura patética de Juan Reyes una dimensión protagonística y convirtiéndolo en el espejo negativo -y premonición de su futuro- del triunfador José Álvarez. Por otra, la muerte del apoderado a manos de Reyes supone un cierre más rotundo (concesión, sin duda, al público cinematográfico), pues con este acto de "justicia poética" se eliminaba el final abierto y más inquietante del drama de Sastre en donde el apoderado, después de muerto su torero, seguía activo y a la caza de nuevas víctimas a las que explotar. No obstante, su muerte en el filme no altera la situación denunciada por Bardem, ya que la dimensión social de la misma impide que sea resuelta por la desaparición de un individuo. Un elemento decisivo para la adscripción al nuevo molde genérico fue la eliminación del color (imprescindible en las películas de tema taurino desde la implantación de la pancromía) a favor de la fotografía en blanco y negro; de modo paradójico, hasta muy finales de los años 60 el blanco y negro se siguió utilizando para los filmes con pretensiones naturalistas o documentales mientras se reservaba el color para aquéllos en los que la dimensión espectacular o la fantástica primaba sobre la realista. Los de tema taurino, que se encuentran, obviamente, entre estos últimos, fueron los primeros en apuntarse a la pancromía, por lo que la opción de Bardem, al filmar en blanco y negro, implicaba una actitud transgresora frente a lo que ya en esos momentos constituía una norma ineludible del género.

Como en otras de sus películas, la trama argumental sirve a Bardem para trazar un panorama de la sociedad española vehiculando a través de ella en la medida de lo posible un mensaje destinado a despertar la conciencia crítica de los españoles adormecida bajo la dictadura franquista. No obstante, no conviene hacer extrapolaciones exageradas pues Bardem, como todos los intelectuales y artistas que querian poner su obra al servicio de un ideal de compromiso político, debió optar por actitudes posibilistas y moverse dentro de los límites impuestos por la censura del Régimen. $Y$ en el caso del cine, había que contar, además, con las concesiones derivadas de los imperativos comerciales; en el filme que nos ocupa la elección del tema taurino pudo estar determinada porque, como apunta Cerón Gómez, tras el fracaso de Sonatas, Bardem era consciente de que sólo tratando temas muy españoles se podía acceder a los mercados internacionales (Cerón Gómez, 1998: 172).

Convendria añadir para terminar algunas observaciones sobre el tratamiento cinematográfico que Bardem impuso al texto de partida, en consonancia con sus propios medios expresivos que suponen, en definitiva, una opción estética, aunque dependiente en gran medida de los recursos técnicos a su alcance. La crítica más joven calificó el lenguaje cinematográfico de Bardem como vetusto y en evidente contraste con la condición transgresora del mensaje que proponía. El cuidadoso tratamiento de la puesta en escena con largos planos secuencia y la tendencia a una disposición triangular de las figuras humanas dentro del cuadro subrayaban, a su entender, el origen teatral de la película.

La actitud más crítica en el momento del estreno fue la manifestada por la revista Film Ideal, cuyos comentarios incidieron en señalar la artificiosidad y la vetustez de las opciones estilisticas del director ${ }^{12}$. El referente desde el que se enfrentan sus críticos a la película de Bardem son los filmes de la nouvelle vague francesa que estaban renovando el lenguaje cinematográfico o las propuestas igualmente innovadoras de directores italianos como Antonioni. El lenguaje de Bardem, sin dejar de ser brillante, les 
resulta viejo, incluso comparándolo con el de otros de sus filmes precedentes como Muerte de un ciclista. Para Juan Cobos, se trataba en definitiva, de un problema de falta de confianza en la imagen que lleva al director a conceder un protagonismo excesivo a la palabra en lugar de permitir que se disuelva en aquélla. En ello insistirá también Félix Martialay al afirmar que el cine puede asimilar "una carga literaria absolutamente desbordada" pero siempre que esa carga "se integre de forma cinematográfica, formando parte de la imagen". Adjetivos como "falso", "artificioso", "teatral", "convencional", "anticuado" y otros similares son repetidos por ambos y por los otros dos críticos -Juan Miguel Lamet y José A. Pruneda- que se ocupan de la película. Evidentemente para todos ellos, el lenguaje de Bardem no había estado en este caso acorde con la intención transgresora de su mensaje, el cual, falto del vehículo que lo hiciera convincente, perdia toda su operatividad ${ }^{13}$.

El ejemplo de $A$ las cinco de la tarde resulta paradigmático para entender cómo la falta de percepción por parte del director de la mutación que se estaba produciendo en los modelos vigentes determinó el rechazo de la película por una crítica que juzgaba ya con un nuevo sistema de valores y para la que las pretensiones "revolucionarias" de la propuesta bardemiana naufragaban en su lenguaje obsoleto. Paradójicamente, nos hallamos ante una situación contraria a la que se planteó con la recepción del texto teatral que sirve de base a la película, ya que una parte considerable de la crítica se mostró reticente ante $L a$ cornada debido a la modernidad de su lenguaje escénico, pues las estrategias desrealizadoras en las que Sastre y Marsillach basaron su propuesta transgredian los patrones de referencia de un público todavía anclado en una desfasada estética naturalista ${ }^{14}$.

Sin abandonar el ámbito de la producción española son otros muchos los títulos que se podrían aducir como prueba de la influencia del molde genérico sobre el proceso de adaptación a la pantalla de un texto literario. Piénsese en la adaptación que Luis Lucia rueda de $L a$ vida es sueño (El príncipe encadenado, 1961) en la que se adecua al modelo del filme de aventuras (revitalizado por las numerosas coproducciones en que se embarca la cinematografía española desde mediados de los 50), que se caracteriza por el rodaje en escenarios naturales, el uso del color, un ritmo narrativo acelerado, la participación de actores internacionales y un elevado presupuesto. Este filme de Lucia supone, pues, el abandono de la artificiosidad, la grandilocuencia y la consideración casi sagrada del texto que habían caracterizado los anteriores acercamientos del cine español a nuestros textos clásicos; basta para comprobarlo comparar el trabajo de Luis Lucia con el llevado a cabo por Gutiérrez Maeso unos años antes al adaptar El Alcalde de Zalamea (1952) o con la versión que Antonio Román rodó de Fuenteovejuna en 1947. Otro ejemplo elocuente lo tenemos en La laguna negra, adaptación que Arturo Ruiz Castillo realizó de La tierra de Alvargonzález en 1947: la leyenda en verso machadiana pierde todos sus elementos míticolegendarios para adecuarse al molde del relato policiacopsicológico y convertirse en una sobria y sólida historia centrada en el análisis del sentimiento de culpabilidad de los protagonistas.

Sobre tales filmes y otros varios habrá que volver con mayor detenimiento para afianzar la tesis que han sustentado las líneas precedentes: la de las inevitables transformaciones que, tanto en el nivel formal como en el del contenido, experimenta cualquier texto literario cuando su traslado a la pantalla se realiza partiendo de un molde fílmico predeterminado. Transformaciones que se suman a otras muchas derivadas de las condiciones del contexto de llegada donde ha de funcionar el nuevo texto-filme.

\section{NOTAS}

* Este trabajo se inscribe en el marco del proyecto de investigación "Teoría y práctica de la adaptación cinematográfica: 1962-1975" (FFI2008-

Recibido: 20 de octubre de 2008 Aceptado: 30 de marzo de 2009 02810), dirigido por José Antonio Pé- rez Bowie (Universidad de Salamanca) y subvencionado por el Ministerio de Ciencia y Tecnología.

1 "En cuanto la industria detecta el asentamiento de un formato en varios segmentos de público evalúa su tamaño e interés, y en caso positivo, 
reproduce esquemas y claves imitables del éxito de modo que la industria (desde distintas productoras y estudios) se pone en algo parecido a la producción en serie, sobre todo si comparamos argumentos, estrellas y estilos en las temporadas altas de la exhibición (...). En cuanto el fenómeno es manifiesto, suele interesar a la crítica. Desde el momento en que parece ensayarse un nuevo formato en una esfera pública, la crítica inicia una investigación retrospectiva para justificar sus orígenes y relaciones, y de esta manera ir delimitando sus caracteristicas en comparación al escenario de los géneros en el momento. Como todo proceso comunicativo, el de la crítica debe también alcanzar cierto umbral de éxito, al menos entre otros críticos, lo cual es imprescindible para que la propuesta genérica se consolide" (Martí, 2005, 438-439).

2 La obra citada de Fuzellier es Cinéma et littérature, Paris, Cerf, 1964.

3 Comenta el ejemplo del film noir que, aunque es heredero de la novela negra, aparte de diferenciarse en varios títulos, no cubre necesariamente las mismas problemáticas formales ni las mismas temáticas. De igual modo, mientras que el melodrama literario se relacionaba con el teatro más que con la novela, no sucede lo mismo en el cine, aparte de que lo que es verdad para el melodrama italiano no lo es para el francés o el americano. Incluso en literatura, las etiquetas genéricas tienen una significación variable según su contexto; sería por ello necesario precisar para cada obra que es objeto de una adaptación la significación del término genérico de referencia según el contexto.

4 Ya en los años previos a la guerra civil, cuando aún no había iniciado su carrera de director, Rafael Gil apostaba por privilegiar el humor como uno de los caminos que podrian dotar de prestigio a la industria cinematográfica española. En un artículo publicado en la revista Popular Film afirmaba: "[al cine español] hay que inyectarle jovialidad, hay que enseñarle a sonreír para que marche por la ruta del humor, que es la ruta por la que René Clair y Alexander Korda impusieron al cinema francés y al inglés hacia el destino de la universalidad; auténtico destino del arte auténtico" ("Cine español", Popular Film, 28.5.1936; reproducido en Fernando Alonso Barahona, 2004, 118).

5 Un detallado análisis de esta adaptación cinematográfica así como de otras basadas en relatos de Wenceslao Fernández Flórez puede hallarse en la tesis doctoral de Héctor Paz Otero (2008).

6 Santos Zunzunegui ha destacado cómo el cine español de la época reformulaba, sobre bases nuevas, tradiciones culturales antiguas, reutilizando las convenciones de géneros como el sainete o el carnaval, o de la comedia costumbrista de corte estridente, vinculada tanto a la zarzuela como al juguete cómico o la farsa (Zunzunegui, 2005, 492).

7 Por ejemplo, la sublevación de los tripulantes de El Dragón contra el capitán Zaldumbide se limita a una breve secuencia nocturna; o la escena culminante de la galerna es una evidente recreación de estudio en la que se intercalaron planos de olas procedentes del filme documental de Flaherty Nanuk el esquimal.

8 Para más información sobre este film, véase Pérez Bowie (2006).

9 La mirada crítica hacia el universo taurino se manifiesta en ocasiones en la literatura española, aunque más habitualmente en el campo de la novela o del ensayo (recuérdese el nombre de Eugenio Noel); no obstante, existía algún ejemplo de antitaurinismo escénico bastante anterior al estreno de La cornada, como Los semidioses, de Juan José Oliver.

10 Alfonso Sastre: "Sobre un film de Bardem", Nuestro Cine, n. 2 (agosto 1961), pp. 24-25.

11 Sobre las vicisitudes de la gestación de este filme, también, al igual que Sonatas, producido por UNINCl, se puede encontrar amplia información en Salvador Marañón, 2006, pp. 336351.

12 Otra revista de referencia en aquellos momentos, Nuestro Cine, mucho más próxima a las posiciones ideológicas de Bardem y de Sastre, recibió el filme con entusiasmo dedicando gran parte de su n. ${ }^{\circ} 2$ (agosto 1961) a publicar el guión completo. En ese número se incluye también el artículo de Alfonso Sastre citado más arriba.

13 "Nada más que la verdad. A las cinco de la tarde, puesta en escena de Juan Antonio Bardem", Film Ideal, n. ${ }^{\circ} 81$ (octubre 1961), pp. 26-27.

14 Para un análisis más completo de esta adaptación véase Pérez Bowie (2007).

\section{BIBLIOGRAFÍA}

AA.W. (2005): La nueva memoria. Historia(s) del cine español, Coruña, Vía Láctea.

Anónimo (1945): "Un realizador entra en campo. Arturo Ruiz-Castillo va a dirigir películas largas. Y para comenzar ha descubierto una nueva cantera cinematográfica: Baroja", Luces. Revista de Espectáculos, II, n. ${ }^{\circ}$ 4, febrero.

Alonso Barahona, Fernando (2004): Rafael Gil. Escritor de cine, Madrid, Egeda. 
Altman, Rick (2000): Los géneros cinematográficos, Barcelona, Paidós.

Becerra, Carmen (ed.) (2005): Lecturas: Imágenes. Reescribir ficciones. Imágenes de la literatura en el cine y en la televisión, Pontevedra, Mirabel.

Catrysse, Patrick (1992): Pour une théorie de l'adaptation filmique. Le film noir américain, Berna, Peter Lang.

Cerón Gómez, Juan Francisco (1998): El cine de Juan Antonio Bardem, Murcia, Universidad y Primavera Cinematográfica de Lorca.

Coremans, Linda (1990): La transformation filmique. Du "Contexto" a "Cadaveri eccelenti", Berne, Peter Lang.

Heredero, Carlos F. (1993): Las huellas del tiempo. Cine español 1950-1961, Madrid y Valencia, Filmoteca Española y Filmoteca de la Generalitat Valenciana.

Martí, Daniel (2005): "Restos útiles del debate en torno al género cinematográfico", en Carmen Becerra (ed.), pp. 435-447.

Naremore, James (ed.) (2000): Film Adaptation, New Brunswick, Rutgers University Press.
Paz Otero, Héctor (2008): Adaptaciones cinematográficas en la década de los cuarenta de las novelas de Wenceslao Fernández Flórez ambientadas en Galicia, Tesis doctoral inédita presentada en la Universidad de Vigo.

Peña Ardid, Carmen (ed.) (1999): Encuentros sobre literatura y cine, Teruel y Zaragoza, Instituto de Estudios Turolenses y Caja de Ahorros de la Inmaculada.

Pérez Bowie, José Antonio (2006): "La novela de Pío Baroja en el cine", Ínsula, 719, noviembre, pp. 33-36.

- (2007): "Alfonso Sastre en el cine. Algunas notas a propósito de La cornada y su versión fílmica (A las cinco de la tarde, de Juan Antonio Bardem)", República de las Letras, 101, pp. 98-112.

Ropars-Wuilleumier, Marie-Claire (1975): Du la littérature au cinéma, Paris, Armand Collin.

- $\quad$ (1981): Le texte divisé, Paris, PUF.

- (1990): Écraniques. Le film du texte, Lille, Presses Universitaires.

Salvador Marañón, Alicia (2006): De Bienvenido, Mr. Marshall a Viridiana. Historia de UNINCl, una productora cinematográfica bajo el franquismo, Madrid, Egeda.

Schaeffer, Jean Marie (1989): Qu'est ce qu'un genre littéraire?, Paris, Seuil.

Serceau, Michel (1999): L'adaptation cinématographique des textes littéraires. Théories et lectures, Liege, Éditions du Céfal.

Stam, Robert (2000): "Beyond Fidelity: The Dialogics of Adaptation", en James Naremore, ed., pp. 54-76.

- (2005). "Introduction: The theory and Practice of Adaptation", en R. Stam \& Alessandra Raengo (eds.), pp. 11-52.

- \& Alessandra Raengo (eds.) (2005): Literature and Film. A Guide to Theory and Practice of Film Adaptation, London, Blackwell.

Vanoye, François (1989): Récit écrit et récit filmique, Paris, Nathan.

- (1996): Guiones modelo y modelos de guión. Argumentos clásicos y modernos en el cine, Barcelona, Paidós.

Villanueva, Darío (1999): "Novela y cine, signos de narración", en Peña-Ardid, Carmen (ed.), pp. 185-209.

Zunzunegui, Santos (2005): "Epílogo: La línea general o las vetas creativas del cine español", en AA.W., pp. 488-504. 